\title{
Persister cells formation and expression of type II Toxin-Antitoxin system genes in Brucella melitensis (16M) and Brucella abortus (B19)
}

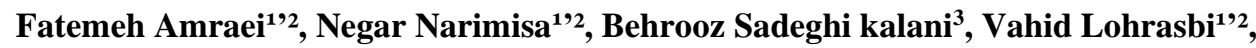 \\ Faramarz Masjedian Jazi ${ }^{12 *}$
}

\author{
Microbial Biotechnology Research Center, Iran University of Medical Science, Tehran, Iran \\ Department of Microbiology, School of Medicine, Iran University of Medical Sciences, Tehran, Iran \\ Clinical Microbiology Research Center, Ilam University of Medical Sciences, Ilam, Iran
}

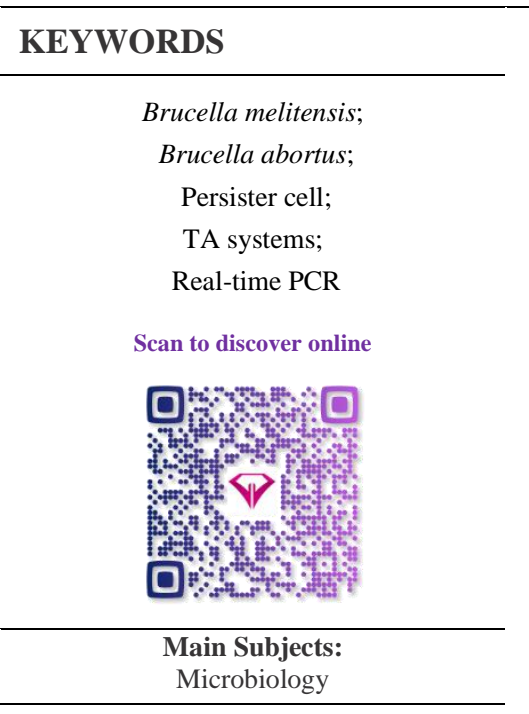

Received 21 Dec 2019;

Accepted 30 Jan 2020;

Published Online 19 Feb 2020;

10.30699/ijp.2020.118902.2294

\section{ABSTRACT}

Background \& Objective: Persister cells are defined as a subpopulation of bacteria that are capable of reducing their metabolism and switching to dormancy in stress conditions. Persister cells formation has been attributed to numerous mechanisms, including stringent response and Toxin-Antitoxin (TA) systems. This study aimed to investigate the hypothetical role of TA systems in persister cells formation of Brucella strains by evaluating toxins of type II TA systems (RelE, Fic, Brn T, $\operatorname{cog}$ T) expression.

Methods: Brucella strains treated with a lethal dose of gentamicin and ampicillin and to determine the number of surviving cells, bacterial colonies were counted at different time intervals. The role of TA systems in persister cell formation was then determined by toxin expression levels using qRT- PCR method.

Results: Our results showed the viability of persister cells after $7 \mathrm{~h}$. The results of relative qRT- PCR showed higher levels of toxin gene expression due to stress conditions, suggesting the possible role of TA systems in persister cells formation and antibiotics tolerance.

Conclusion: The results of this study showed that considering the importance of persistence and the tolerance to antibiotics, further studies on persister cells formation and related genes such as the TA system genes in Brucella strains might help us to identify the precise mechanisms leading to persister cells formation.

Corresponding Information:

Faramarz Masjedian jazi, Ph.D. of Microbiology, Department of Medical Microbiology, School of Medicine, Iran University of Medical Sciences, Tehran, Iran, Email: Masjedian.f@iums.ac.ir

Copyright $\left({ }_{0}\right.$ 2020. This is an open-access article distributed under the terms of the Creative Commons Attribution- 4.0 International License which permit Share, copy and redistribution of the material in any medium or format or adapt, remix, transform, and build upon the material for any purpose, even commercially.

\section{Introduction}

Brucellosis is a zoonotic disease that causes abortion, genital infections and fetal death in animals. In humans, this highly diverse illness initially presents as fever, malaise, and myalgia and may later develop into a chronic illness affecting various organs and tissues such as the spleen, brain, joints, heart, liver and bone marrow (1-3). Brucellosis is an endemic disease in the Middle East, the Mediterranean countries and East Asia and Latin America. World health organization (WHO) has reported every year 500,000 new cases of brucellosis diagnosed in above regions. The causative agents of brucellosis are facultative intracellular, coccobacilli, aerobic and gram-negative bacteria belonging to the genus Brucella $(4,5)$.

Based on the differences in host specificity and biochemical analysis, ten species are identified in the genus Brucella including B. melitensis, B. abortus, $B$. ovis, B. suis, B. canis, B. neotomae, B. inopinata, $B$. ceti, B. microti, and B. pinnipedialis (6). However, the most prevalent pathogenic species in humans and animals are Brucella melitensis and Brucella abortus (7). Brucellosis disease appears in the forms of the acute, sub-acute or chronic (8). Treatment of chronic infections is complicated by both bacterial persistence and resistance, two distinct phenomena occurring through unrelated mechanisms. Resistance is caused by genetic variations, which result in the alteration of antibiotic targets to reduce antibiotic binding and efficacy. As a result, resistant bacteria are able to survive and even grow in the presence of antibiotics (9). When the antibiotic concentration exceeds a certain threshold, only so called "persister" cells can survive (10).

These cells were primarily detected in 1944 by Joseph Bigger who noticed the survival of a subpopulation of Staphylococcus aureus which were being exposed to a lethal dose of penicillin. Persister cells have a significant role in the progression of 
chronic infections such as tuberculosis, cystic fibrosis, and candidiasis $(11,12)$

Although there are little data about bacterial persistence, recent studies represent toxin-antitoxin (TA) systems have a major role in persister cells formation (13).

TA systems are abundant small modules in the genomes of bacteria and archaea, generally composed of two elements: a stable toxin that targets an essential cellular process and a labile antitoxin that inhibits the toxins deleterious activity. Several distinct families of TA systems have been identified on bacterial chromosomes that regulate stress survival and persister cells formation.

TA systems are currently divided into six different classes (I-VI), in which the type II of these systems has mostly been studied. In the type II TA system, two protein genes (toxin and antitoxin) are co-expressed $(14,15)$. In normal conditions, antitoxin inhibits the activity of the stable toxin by forming a tight proteinprotein complex (16). In the stress condition, the labile antitoxin is selectively degraded by cellular proteases such as Lon and clpXP. Destruction of antitoxins makes toxin to target the essential bacterial processes (protein translation, and cell-wall synthesis, DNA replication) and triggers various functions such as switching of bacteria into dormant, stress management, bacterial persistence $(17,18)$.

Therefore, this research aimed to study persister cells formation and expression levels of type II TA system toxin genes in Brucella spp, treated with gentamicin and ampicillin.

\section{Materials and Methods \\ Bacterial Strains and DNA Preparation}

In this study, two standard strains of Brucella spp, including Brucella melitensis (16M) and Brucella abortus (B19) were used from the reference laboratory and the school of medicine of Iran University of Medical Sciences, Iran. Strains were cultured on Brucella agar (Merck, Darmstadt, Germany) and incubated at $37^{\circ} \mathrm{C}$ with $5 \% \mathrm{CO}_{2}$ for $48 \mathrm{~h}$. Genomic DNA extraction was performed using Gene All Kit (South Korea) according to the manufacturer's instructions. The DNA purity and concentration were measured using a NanoDrop ${ }^{\mathrm{TM}}$ spectrophotometer (Thermo Fisher Scientific, Waltham, MA, USA). The absorbance ratio at $260 \mathrm{~nm}$ and $280 \mathrm{~nm}$ (A260/280) was used to assess the purity of DNA and the ratio of $\sim 1.8$ was considered as purity for extracted DNA. DNA was stored at $-20^{\circ} \mathrm{C}$ until the Polymerase chain reaction (PCR) was carried out $(4,19)$.

\section{Identification of TA Systems and Primer Design}

Complete Genome sequences of B. melitensis (16M) and $B$. abortus (B19) were obtained from NCBI GenBank and TADB database (http://bioinfomml.sjtu.edu.cn/TADB/) to identify type II TA systems. Moreover, NCBI BLAST was used to find homologous of type II TA systems. Specific primers were designed by using OLIGO software V. 7.56 (Table 1).

Table 1. Primers used for both PCR and qRT-PCR studies.

\begin{tabular}{|c|c|c|c|c|}
\hline Primer Name & Primer sequence $\left(5^{\prime} \rightarrow 3^{\prime}\right)$ & $\begin{array}{l}\text { Amplicon } \\
\text { size (bp) }\end{array}$ & Annealing temperature & Reference \\
\hline \multirow{2}{*}{ RelE } & F: TGCAATTGAGCGAAGATTTG & \multirow{2}{*}{208} & \multirow{2}{*}{$57^{\circ} \mathrm{C}$} & \multirow{2}{*}{ In this study } \\
\hline & R: TCATCCGGTGGTAAGATTGG & & & \\
\hline \multirow{2}{*}{ Fic } & F: CATCAGGAACAACTGCGCTT & \multirow{2}{*}{111} & \multirow{2}{*}{$59^{\circ} \mathrm{C}$} & \multirow{2}{*}{ In this study } \\
\hline & R: ATCGGGATTGCCATAGGCTT & & & \\
\hline \multirow{2}{*}{$B r n T$} & F:ACAGACCAACATTGCCAAGC & \multirow{2}{*}{106} & \multirow{2}{*}{$59^{\circ} \mathrm{C}$} & \multirow{2}{*}{ In this study } \\
\hline & R: GATTGCCATCAGGCGATCTG & & & \\
\hline \multirow{2}{*}{$\operatorname{Cog} T$} & F: ATCTGGAAGCCGTCATGGAA & \multirow{2}{*}{122} & \multirow{2}{*}{$59^{\circ} \mathrm{C}$} & \multirow{2}{*}{ In this study } \\
\hline & R:GGCCATGACAATGCTGGAAT & & & \\
\hline \multirow{2}{*}{$16 S r R N A$} & F: CAGATTACGCAAGCAGCCTT & \multirow{2}{*}{134} & \multirow{2}{*}{$58^{\circ} \mathrm{C}$} & \multirow{2}{*}{ In this study } \\
\hline & R: TCCTCGACGCTTAGTGTCTC & & & \\
\hline
\end{tabular}

\section{PCR Analysis of TA System Genes}

PCR assay was used to detect the presence of the type II TA system genes (RelE, Fic, Brn T, $\operatorname{Cog} T$ ) in Brucella spp.

PCR amplifications was performed in a final volume of $25 \mu \mathrm{L}$. Each PCR reaction mixture contained $8 \mu \mathrm{L}$ Master mix 1X (Ampliqon Co, Denmark), $1 \mu \mathrm{L}$ template DNA $(0.5 \mu \mathrm{g}), 1 \mu \mathrm{L}$ of each forward and reverse primers and sterile distilled water up to $25 \mu \mathrm{L}$.

PCR amplification was performed in a DNA thermal cycler (PeqLab, Germany). PCR program consisted of an initial denaturation step at $95^{\circ} \mathrm{C}$ for $4 \mathrm{~min} ; 35 \times 95^{\circ} \mathrm{C}$ for $45 \mathrm{~s}$, annealing at $60^{\circ} \mathrm{C}$ for $45 \mathrm{~s}$, and extension at $72^{\circ} \mathrm{C}$ for $30 \mathrm{~s}$, with a final extension step at $72^{\circ} \mathrm{C}$ for 3 min. PCR products were purified and analyzed on $1.5 \%$ (w/v) agarose gel in TBE buffer at 85 volt and $25 \mathrm{~mA}$, for 40 min using the $50 \mathrm{bp}$ ladder (Pishgam, Iran) as the molecular weight standard $\left({ }^{\circ}\right)$.

\section{Determination of Minimum Inhibitory Concentration (MIC)}

The microdilution method was used to determine the MIC of Brucella spp, according to the National 
Committee for Clinical Laboratory Standards (NCCLS). The study was done in accordance with good clinical practice under a biocontainment level 3 biosafety cabinet (20). To determine the MICs of gentamicin and ampicillin (Sigma Aldrich), $100 \mu \mathrm{L}$ of $0.5 \mathrm{McF}$ arland overnight bacterial culture (dilution of 1:100 in MHB) and different concentrations of antibiotic solution were added to the 96-well microtiter plates and incubated at $37^{\circ} \mathrm{C}$ with $5 \% \mathrm{CO}_{2}$ for $48 \mathrm{~h}$.

The MIC was considered as the lowest concentration of antibiotic that prevented the visible bacterial growth after $48 \mathrm{~h}$ of incubation. MIC values for the studied antibiotics were independently determined three times (21).

\section{Persister Cell Formation Assay}

To measure the number of persister cells, $B$. melitensis (16M) and B. abortus (B19) was cultured overnight and diluted to the proportion of $1: 100$ in tryptic soy broth. Bacterial culture was incubated at $37^{\circ} \mathrm{C}$ with $5 \% \mathrm{CO} 2$ on a shaker at $200 \mathrm{rpm}$ until the absorbance at $600 \mathrm{~nm}$ reached 0.25 (logarithmic phase). Then, was added to the culture at a concentration of gentamicin $40 \mu \mathrm{g} / \mathrm{mL}$ (60x MIC) and $100 \mu \mathrm{g} / \mathrm{mL}$ (50x MIC) of ampicillin. Then, $1 \mathrm{~mL}$ of culture was washed twice by $0.85 \%$ sterile saline solution to remove the antibiotic after 1, 3, 5, 7, and $18 \mathrm{~h}$. Serial dilution of bacterial culture was prepared and each dilution was poured onto Brucella agar. Plates were then incubated at $37^{\circ} \mathrm{C}$ with $5 \% \mathrm{CO}_{2}$ for $48 \mathrm{~h}$. Finally, colonies were counted in order to detect the presence of the bacterium on agar plate.

\section{Quantitative Real-Time PCR (qRT-PCR)}

Total RNA of B. melitensis (16M) and B. abortus (B19) was extracted using high pure RNA isolation kit
(Roche kit, Germany) 7h after of treatment with antibiotics gentamicin and ampicillin. Total RNA of untreated B. melitensis (16M) and B. abortus (B19) was also extracted as control. The quantity and quality of RNA were assessed using the NanoDrop spectrophotometer (Thermo Fisher Scientific, USA) and gel electrophoresis analysis. In order to remove DNA contamination, extracted RNA was treated with DNase1 (Roche, Germany) according to the manufacturer's protocol. Total RNA was reverse transcribed to cDNA using the cDNA Synthesis Kit (Takara, Japan).

The qRT-PCR (three replicates) assay for each gene was performed on Rotor-Gene thermal cycler according to the following program: one cycle of $95^{\circ} \mathrm{C}$ for $12 \mathrm{~min}, 40$ cycles of $95^{\circ} \mathrm{C}$ for $10 \mathrm{~s}$, and one cycle of $60^{\circ} \mathrm{C}$ for $45 \mathrm{~s}$.

A housekeeping gene called 16S rRNA was used as the internal control for normalization of mRNA levels and fold changes and mRNA expression was calculated by the $2^{\wedge}(-\Delta \Delta C T)$ method (22).

\section{Statistical Analysis}

Data obtained from the mRNA expression analysis were presented as means \pm standard error of three independent assessments. Values obtained for the expression of each individual gene exposed to antibiotics were compared using one-way analysis of variance (ANOVA) test followed by Dunn-Test and Friedman test for multiple comparisons by Prism 8 (GraphPad Software, Inc).

\section{Results}

\section{TA System Genes Detection by PCR}

We investigated the existence of type II TA systems in B. melitensis (16M) and B. abortus (B19). Our results revealed the presence of all of the studied genes coding for type II TA system in this strains (Figure 1).

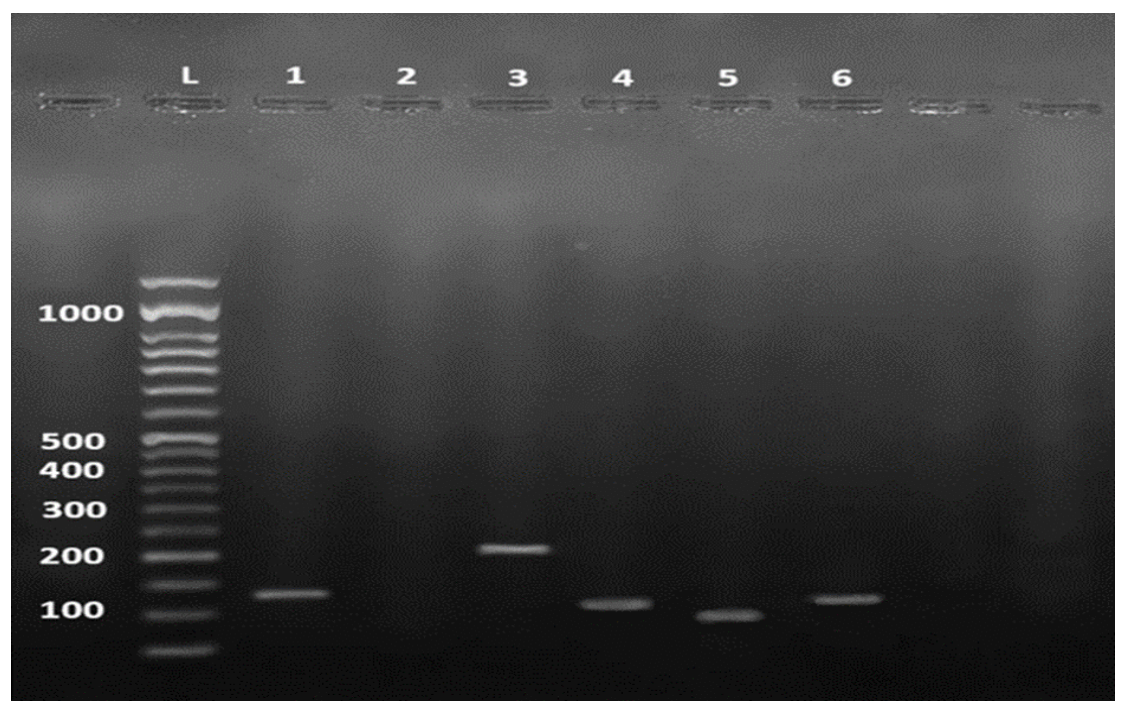

Fig. 1. The presence of TA systems detection by PCR in Brucella. Lanes 1-6 respectively contains: 50 bp DNA ladder, 1: positive control 16S rRNA gene (134 bp), 2: negative control, 3: RelE (208 bp), 4: Fic (111bp), 5: Brn T (106 bp) ,6: CogT (122 bp).

\section{Antimicrobial Susceptibility Testing in Brucella spp.}

In this study, we first determined the MIC ranges of gentamicin and ampicillin against Brucella spp, using the broth micro dilution assay. The MIC ranges for the selected antibiotics were for Brucella 
melitensis (16M) and Brucella abortus (B19) $2 \mu \mathrm{g} / \mathrm{mL}$ and $0.5 \mu \mathrm{g} / \mathrm{mL}$, respectively.

\section{Persister Cells Populations in Brucella spp.}

As shown in Figure 2, to evaluate persister cells Brucella spp, culture was treated with gentamicin and ampicillin during the exponential phase. Colonies were counted and colony forming unit calculations indicated that after $1 \mathrm{~h}$, the number of viable cells reduced significantly, while after $7 \mathrm{~h}$, the number of viable cells remained the same. Survival curves of plateau-phase demonstrated the survival of persister cells.

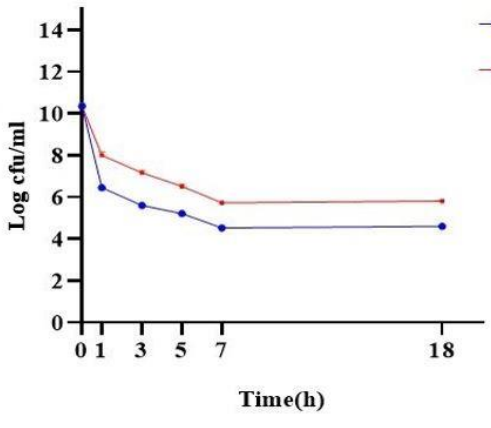

A
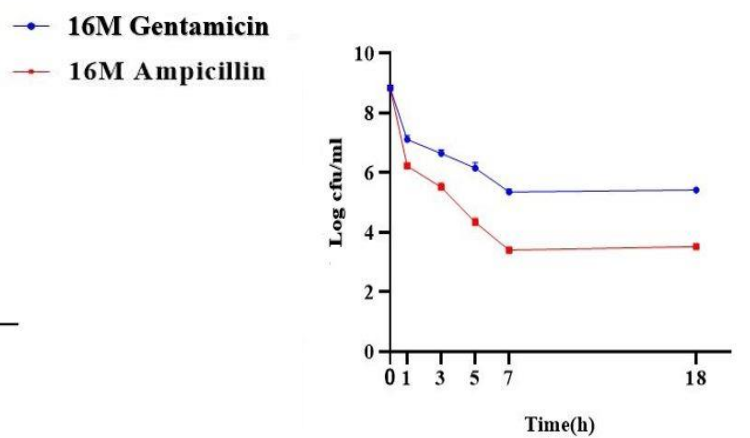

B

Fig. 2. Stabilization test for bacteria through colony count (CFUs). (Fig. 2 A) Experiment for persister cells heritability using gentamicin and ampicillin antibiotics against Brucella melitensis (16M) and (Fig. 2 B) Brucella abortus.

persister cells of $16 \mathrm{M}$ and B19 with lethal concentration of gentamicin and of ampicillin were performed at different times to assess the number of colonies that survived the cells. Error bars indicate standard deviation of three independent replicates $(P<0.01$ by Friedman test $)$.

\section{Relative Gene Expression}

Our qRT-PCR data analysis showed that all the studied type II TA systems (RelE, Fic, Brn T, CogT) in the selected isolates had a higher expression levels than the control sample (Figure 3).
Furthermore, statistical analysis results showed that levels of TA expression after antibiotics treatment in the four groups (RelE, Fic, Brn T, $\operatorname{Cog} T$ ) was statistically significant at $95 \%$ confidence levels $(P<0.05)$ (Figure 3).

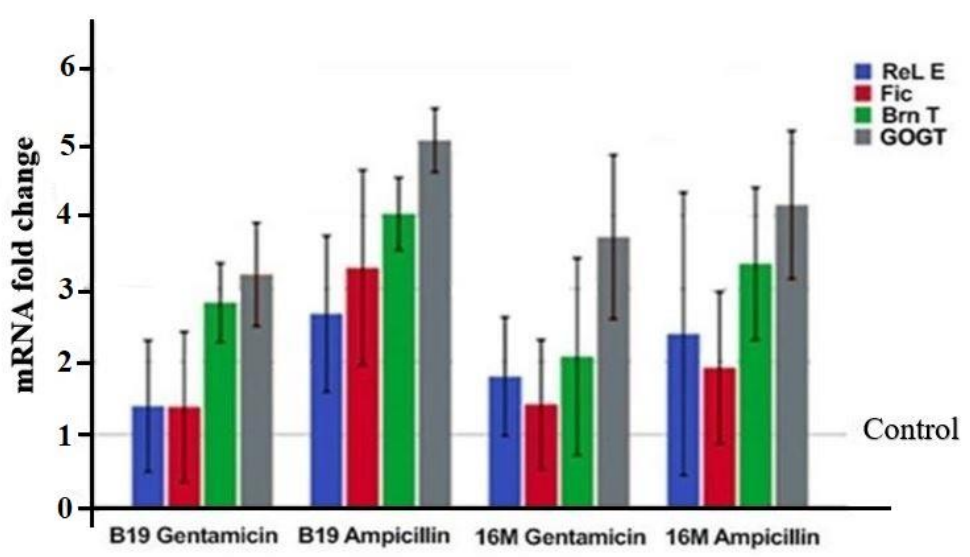

Fig. 3. Gene expression analysis by Real-time PCR. Relative expression is normalized for Brucella melitensis (16 M) and Brucella abortus (B19) with housekeeping 16S rRNA gene $(P<0.05)$.

Bars represent the mean \pm SD of three independent replicates $(P<0.05$ by Friedman test $)$.

\section{Discussion}

According to studies, persister cells are responsible for antibiotic tolerance, bacterial survival in biofilms, and development of recurrent infection caused by different bacteria $(23,24)$. In our study, we examined persister cells formation in Brucella spp, treated with gentamicin and ampicillin. Considering the association between type II TA system toxins and persistence, after the treatment of Brucella spp, with a lethal dose of gentamicin and ampicillin, to determine the effect of TA systems on persister cells formation, RNA of Brucella spp, was extracted after $7 \mathrm{~h}$ treatment with gentamicin and ampicillin and expression levels of four 
type II TA system toxins were measured using relative qRT-PCR.

However, persister cells for Brucella spp, were formed after challenge with antibiotics and the results showed that the number of viable cells was altered according to the number of colony count. Furthermore, our results showed that increase in transcription levels of RelE, Fic, Brn T, $\operatorname{Cog} T$ compared to the control strains. Previous studies have indicated the role of TA systems in persister cell formation. TA systems were at first identified in plasmids accounting for postsegregational killing mechanism (25). Thereafter, many of these systems were found on bacterial chromosomes. Chromosomal TA systems affect essential cellular mechanisms by which bacterial cells can survive in stress conditions (26).

According to studies, six different classes of TA systems have been identified among which type II systems is known to have a role in persister cells formation. In type II TA systems, protein antitoxin has two domains; one domain binds a palindromic sequence of the promoter leading to the repression of type II TA operon, while the second domain binds the cognate toxin leading to its inhibition (17). In the stress condition, unstable antitoxin is degraded by proteases such as ClpXP and ClpAP, hence the free toxin can affect major cellular processes leading to bacterial persistence and dormancy (27).

Under stress conditions, most type II toxins are able to inhibit translation by different mechanisms. For instance, vapC toxin cleaves tRNA ${ }^{\mathrm{fMet}}$ by its RNase activity, which can further block protein synthesis. The Doc toxin binds the $30 \mathrm{~S}$ ribosomal subunit leading to the inhibition of translation and growth arrest in bacterial cells (28).

Harris Moyed et al, in 1983 reported that two mutations in hipA gene increased persistence in $E$. coli for 1000 fold. HipA gene in E. coli was recognized as the first gene of TA system that plays a role in persistence (29). HipA is a toxin of hipAB TA system that phosphorylates elongation factor $\mathrm{Tu}(\mathrm{EF}-\mathrm{Tu})$ by its kinase activity, causing reduction in translation and induction of persistence $(30,31)$. Vázquez-Laslop et al., demonstrated that the ectopic expression of RelE and $M a z F$ toxins in $E$. coli can lead to bacterial antibiotic tolerance and persistence (32).

In another study, it was shown that exposure to ciprofloxacin in E. coli increased the level of TisB toxin and increased the number of persister cells. However, the most direct evidence for a role of TA systems modules in persister cells formation is derived from studies showing that mutations in the hipBA TA system of $E$. coli can modulate the frequency of persister cell formation. Similarly, it has been reported that inactivation of the RelE genes in Mycobacterium tuberculosis may influences on the frequency of persister cells formation (33).

Our results showed increase in transcription levels of RelE, Fic, Brn T, $\operatorname{Cog} T$ compared to the control strain, suggesting the possible role of TA systems in persistence and antibiotic tolerance.

Furthermore, our study showed increase in $\operatorname{Cog} T$ gene expression which was the highest expression level among the studied toxins, suggesting that toxin $\operatorname{Cog} T$ may have the greatest effect on the production of persistent cells in Brucella spp. PSI-BLAST results showed that $\operatorname{Cog} T$ contains three highly conserved polar groups that could form an active site. These are an arginine, glutamate and serine, the RES domain. RES is found widely distributed in bacteria.

Since antibiotic tolerance caused by persister cells results in treatment failure and chronic infections, investigating the genes related to persistence such as TA systems help us to recognize the precise mechanisms linked to persistence.

\section{Conclusion}

Chronic brucellosis is a major problem in medical science, as it causes many complications in patients. According to the results, there may be a link between the persistence of this bacterium and the TA system genes, which can be a way of treating the disease. The results of this study indicate that RelE, Fic, Brn T, and $\operatorname{Cog} T$ genes may play a role in the persistence of the Brucella bacteria. Also, the $\operatorname{Cog} T$ gene expression has increased in comparison with other genes in two standard strains. But the mechanism of this $\operatorname{Cog} T$ system is still unknown. Although further studies are needed to determine the exact role of these genes, including; extruding these genes, making mutant strains, examining animal models, and cell culture studies

\section{Acknowledgements}

This study was financially supported by a research grant (No.33075) for a M.Sc thesis in Iran University of Medical Sciences (Tehran, Iran), for which we are very grateful.

\section{Conflict of Interest}

The authors declared that there is no conflict of interest regarding the publication of this article.

\section{References}

1. Probert WS, Schrader KN, Khuong NY, Bystrom SL, Graves MHJJocm. Real-time multiplex PCR assay for detection of Brucella spp., B. abortus, and B. melitensis. 2004;42(3):1290-3. [DOI:10.1128/JCM.42.3.1290-1293.2004] [PMID] [PMCID]

2. Eskandari-Nasab E, Moghadampour M, Hasani SS, Hadadi-fishani M, Mirghanizadeh-Bafghi SA, Asadi-Saghandi A, et al. Relationship between gamma-interferon gene polymorphisms and susceptibility to brucellosis infection. Microbiol Immunol. 2013;57(11):785-91. [DOI:10.1111/1348-0421.12093] [PMID]

3. López-Goñi I, García-Yoldi D, Marín CM, de Miguel MJ, Barquero-Calvo E, Guzmán-Verri C, 
et al. New Bruce-ladder multiplex PCR assay for the biovar typing of Brucella suis and the discrimination of Brucella suis and Brucella canis. Veterinary microbiology. 2011;154(1-2):152-5. [DOI:10.1016/j.vetmic.2011.06.035] [PMID]

4. Jazi FM, Mirnejad R, Piranfar V, Mozafari NA, Salehi TZ, Khormali M, et al. Real-time PCR and high-resolution melt analysis methods for detection of pathogenic species of Brucella. 2017;41(6):325-31. [DOI:10.1515/labmed-20170030]

5. Irajian GR, Jazi FM, Mirnejad R, Piranfar VJIjop. Species-specific PCR for the diagnosis and determination of antibiotic susceptibilities of Brucella strains isolated from Tehran, Iran. 2016;11(3):238.

6. Kang S-I, Her M, Kim JW, Kim J-Y, Ko KY, Ha $\mathrm{Y}-\mathrm{M}$, et al. Advanced multiplex PCR assay for differentiation of Brucella species. 2011;77(18):6726-8. [DOI:10.1128/AEM.0058111] [PMID] [PMCID]

7. Mirkalantari S, Zarnani A-H, Nazari M, Irajian GR, Amirmozafari NJAocm, antimicrobials. Brucella melitensis VirB12 recombinant protein is a potential marker for serodiagnosis of human brucellosis. 2017;16(1):8. [DOI:10.1186/s12941017-0182-4] [PMID] [PMCID]

8. khadivi $r$, imani $r$, salehi $s$, dehghan $m$. The incidence rate of chronic brucellosis following one-year antibiotic therapy in Koohrang district of Chaharmahal \& Bakhtyari province \% J Journal of Shahrekord Uuniversity of Medical Sciences. 2006;8(3):54-61.

9. Kwan BW, Valenta JA, Benedik MJ, Wood TKJAa, chemotherapy. Arrested protein synthesis increases persister-like cell formation. 2013;57(3):1468-73. [DOI:10.1128/AAC.0213512] [PMID] [PMCID]

10. Gallo SW, Donamore BK, Pagnussatti VE, Ferreira CAS, de Oliveira SDJFm. Effects of meropenem exposure in persister cells of Acinetobacter calcoaceticus-baumannii. 2017;12(2):131-40. [DOI:10.2217/fmb-20160118] [PMID]

11. Bigger J. Treatment of Staphyloeoeeal Infections with Penicillin by Intermittent Sterilisation. Lancet. 1944:497-500. [DOI:10.1016/S01406736(00)74210-3]

12. Fauvart M, De Groote VN, Michiels JJJomm. Role of persister cells in chronic infections: clinical relevance and perspectives on anti-persister therapies. 2011;60(6):699-709. [DOI:10.1099/jmm.0.030932-0] [PMID]

13. Shah D, Zhang Z, Khodursky AB, Kaldalu N, Kurg K, Lewis KJBm. Persisters: a distinct physiological state of E. coli. 2006;6(1):53. [DOI:10.1186/1471-2180-6-53] [PMID] [PMCID]
14. Kędzierska B, Hayes FJM. Emerging roles of toxin-antitoxin modules in bacterial pathogenesis. 2016;21(6):790.

[DOI:10.3390/molecules21060790]

[PMID] [PMCID]

15. Mohammadzadeh R, Shivaee A, Ohadi E, Kalani BSJIJoPR, Therapeutics. In Silico Insight into the Dominant Type II Toxin-Antitoxin Systems and Clp Proteases in Listeria monocytogenes and Designation of Derived Peptides as a Novel Approach to Interfere with this System. 2019. [DOI:10.1007/s10989-019-09868-6]

16. Masuda H, Inouye M. Toxins of prokaryotic toxinantitoxin systems with sequence-specific endoribonuclease activity. Toxins. 2017;9(4):140. [DOI:10.3390/toxins9040140] [PMID] [PMCID]

17. Yang QE, Walsh TRJFmr. Toxin-antitoxin systems and their role in disseminating and maintaining antimicrobial resistance. 2017;41(3):343-53

[DOI:10.1093/femsre/fux006] [PMID] [PMCID]

18. Muthuramalingam M, White J, Bourne CJT. Toxin-antitoxin modules are pliable switches activated by multiple protease pathways. 2016;8(7):214. [DOI:10.3390/toxins8070214] [PMID] [PMCID]

19. Hashemifar I, Masjedian Jazi F, Yadegar A, Amirmozafari N. Prevalence of proline racemase/ hydroxyproline epimerase gene in human brucella isolates in Iran. Med $\mathbf{J}$ Islam Repub Iran. 2017;31:57. [DOI:10.14196/mjiri.31.57] [PMID] [PMCID]

20. Trott DJ, Abraham S, Adler B. Antimicrobial Resistance in Leptospira, Brucella, and Other Rarely Investigated Veterinary and Zoonotic Pathogens. Microbiol Spectr. 2018;6(4). [DOI:10.1128/microbiolspec.ARBA-0029-2017]

21. Megaw J, Gilmore BF. Archaeal Persisters: Persister Cell Formation as a Stress Response in Haloferax volcanii. Front Microbiol. 2017;8:1589. [DOI:10.3389/fmicb.2017.01589] [PMID] [PMCID]

22. Livak KJ, Schmittgen TD. Analysis of relative gene expression data using real-time quantitative PCR and the 2(-Delta Delta C(T)) Method. Methods. 2001;25(4):402-8. [DOI:10.1006/meth.2001.1262] [PMID]

23. Lewis K. Persister cells and the riddle of biofilm survival. Biochemistry (Moscow). 2005;70(2):267-74. [DOI:10.1007/s10541-0050111-6] [PMID]

24. Ren H, He X, Zou X, Wang G, Li S, Wu Y. Gradual increase in antibiotic concentration affects persistence of Klebsiella pneumoniae. Journal of Antimicrobial Chemotherapy. 2015;70(12):3267-72. [DOI:10.1093/jac/dkv251] [PMID] 
25. Gerdes K, Rasmussen PB, Molin S. Unique type of plasmid maintenance function: postsegregational killing of plasmid-free cells. Proceedings of the National Academy of Sciences. 1986;83(10):3116-20.

[DOI:10.1073/pnas.83.10.3116] [PMID] [PMCID]

26. Page R, Peti WJNcb. Toxin-antitoxin systems in bacterial growth arrest and persistence. 2016;12(4):208. [DOI:10.1038/nchembio.2044] [PMID]

27. Muthuramalingam M, White J, Bourne C. Toxinantitoxin modules are pliable switches activated by multiple protease pathways. Toxins. 2016;8(7):214. [DOI:10.3390/toxins 8070214] [PMID] [PMCID]

28. Holden DW, Errington J. Type II Toxin-Antitoxin Systems and Persister Cells. MBio. 2018;9(5). [DOI:10.1128/mBio.01574-18] [PMID] [PMCID]

29. Moyed HS, Bertrand KPJJob. hipA, a newly recognized gene of Escherichia coli K-12 that affects frequency of persistence after inhibition of murein synthesis. 1983;155(2):768-75. [DOI:10.1128/JB.155.2.768-775.1983] [PMID] [PMCID]
30. Germain E, Roghanian M, Gerdes K, Maisonneuve E. Stochastic induction of persister cells by HipA through (p) ppGpp-mediated activation of mRNA endonucleases. Proceedings of the National Academy of Sciences. 2015;112(16):5171-6. [DOI:10.1073/pnas.1423536112] [PMID] [PMCID]

31. Schumacher MA, Piro KM, Xu W, Hansen S, Lewis K, Brennan RG. Molecular mechanisms of HipA-mediated multidrug tolerance and its neutralization by HipB. Science. 2009;323(5912):396-401.

[DOI:10.1126/science.1163806]

[PMID] [PMCID]

32. Vázquez-Laslop N, Lee H, Neyfakh AAJJob. Increased persistence in Escherichia coli caused by controlled expression of toxins or other unrelated proteins. 2006;188(10):3494-7. [DOI:10.1128/JB.188.10.3494-3497.2006] [PMID] [PMCID]

33. Butt A, Higman VA, Williams C, Crump MP, Hemsley CM, Harmer N, et al. The HicA toxin from Burkholderia pseudomallei has a role in persister cell formation. Biochem $\mathrm{J}$. 2014;459(2):333-44. [DOI:10.1042/BJ20140073] [PMID] [PMCID]

\section{How to Cite This Article}

Amraei, F., Narimisa, N., Sadeghi, B., Lohrasbi, V., Masjedian Jazi, F. Persister cells formation and expression of type II Toxin-Antitoxin system genes in Brucella melitensis (16M) and Brucella abortus (B19). Iranian Journal of Pathology, 2020; 15(2): 127-133. doi: 10.30699/ijp.2020.118902.2294 